\begin{tabular}{c} 
journal homepage: http://ijiemjournal.uns.ac.rs/ \\
International Journal of Industrial \\
Engineering and Management \\
Volume $11 / \mathrm{No} 2 / \mathrm{June} 2020 / 73-80$ \\
\hline
\end{tabular}

Original research article

\title{
Cleaner Production Initiatives in a Diesel Engines Factory
}

\author{
L.F.R. Pinto ${ }^{a}$, G.C. Oliveira Neto ${ }^{a}$, G. Mummolo $^{b}$, S. Digiesi ${ }^{b}$, F. Facchini $^{b *}$, P. Centoamore ${ }^{a}$ \\ a Nove de Julho University, Department of Industrial Engineering, São Paulo, Brazil; \\ b Polytechnic University of Bari, Department of Mechanics, Mathematics and Management, Bari, Italy
}

\section{A B STR A C T}

This paper presents a case study conducted in a Diesel engines manufacturer, which adopted a Cold Test machine to perform the final check of engines in the assembly line. The overall aim of this investigation was evaluating the economic and environmental advantages obtained by the adoption of the Cold Test machine. The results showed cost saving of USD $558,012.67$ per year. The investment required, USD 2.1millions, returned in three years and ten months. The environmental assessment identified the reduction of the mass intensity per abiotic, biotic, water and air compartments, total of $178,420,306.06 \mathrm{~kg}$ resources conservation per year.
ARTICLE INFO

Article history:

Received September 25, 2019

Revised February 12, 2020

Accepted February 18, 2020

Published online March 26, 2020

Keywords:

Cold test;

Cleaner production;

Economic gain;

Environmental advantage;

Mass intensity factor

*Corresponding author:

Francesco Facchini

francesco.facchini@gmail.com

\section{Introduction}

Automakers perform several checks in the vehicles assembly process to assure the high quality level of its products. The internal combustion engine, as the main part of vehicle, requires final check of parameters such as performance and leakage. For this validation, a traditional checking process named Hot Test simulates the vehicle conditions by means of connecting the engine to a dynamometer [1]. Other engine checking process called Cold Test is a more efficiency method to verify the performance and assure the quality of internal combustion engines [2]. The main difference between these two methods is that the Cold Test does not require combustion. The Cold Test catches different forms of wave emission to verify the anomalies by means of torque, pressure and vibration measurements [1].

The raise of Cold Test in Diesel engines has been stimulated by market requirements, shorter test cycle time and lower environmental impact than the Hot Test [1]. The excellent performance in terms of reliability, flexibility, productivity and sustainability are key factors to keep the competitiveness of modern manufacturing systems [3,4]. In this sense, companies have been seeking solutions that contribute to increase the operational efficiency by reducing costs and consumption of natural resources $[5,6]$. In this 
context, the Cold Test is a sustainable process that met the three pillars of the Triple Bottom Line [2]. The use of Cold Test offers advantages compared to Hot Test related to the accuracy of failures diagnosis, test cycle time, consumptions of fuel, water and energy and pollutant gases emissions [7].

The definition of Cleaner Production (CP) is the strategy that aims the integration of environmental preservation to economic advantages [8]. This concept has been expanded toward a sustainability orientation [9]. CP leads to integration of the preventive environmental strategies to processes, products and services aiming to increase the efficiency and to minimize the risks to people and the environment $[10,11]$. In addition, CP is a sustainable competitive advantage taking into account the shortage of natural resources [12].

The increasing globalization of automotive market has stimulated companies at finding solutionsto keep the competitiveness level for business continuity [13]. The automotive industry has implemented $\mathrm{CP}$ practices aimed at reducing greenhouse gas emissions, minimizing losses and waste generation of the production system, mitigating the use of hazardous chemical products, and increase the efficiency of thenatural resources consumption [14]. In this sense, managers encourage the adoption of $\mathrm{CP}$ initiatives aiming to obtain operational cost saving and environmental advantages [15]. Actions such as housekeeping and regular maintenance using quality control systems may genuinely reduce the amount of waste with low investment compared to structural changes [16].

In this context, studies in the automotive sector showed the positive effects of $\mathrm{CP}$ initiatives in several countries. In Spain, the installation of a closed-loop system reduced $95 \%$ of the residual contaminants, decreased $33 \%$ the consumption of drink water and $50 \%$ of cost saving by means of the water treatment in-house [17]. In Canada, the CP adoption enabled annual reduction of 2 tons of GHG emissions, $810 \mathrm{~m}^{3}$ water consumption and generation of 55 tons of hazardous waste, reaching the cost saving of USD 162 thousand per year [18].

In Australia, a study in four companies that implemented CP actions revealed reduction of: (i) energy consumption and addition revenues of USD 690 thousand through the sale of sludge from the wastewater treatment station; (ii) material consumption by means of recycling of packaging that result saving of USD 24 thousand; (iii) waste and increase the reuse of detergents in process that result USD 144 thousand; and (iv) savings of USD 312 thousand as a result of the recycling, reuse and remanufacture of polystyrene [19].

In South Korea, automobiles manufacturers improved theirs operational processes to reduce energy consumption and $\mathrm{CO}_{2}$ emission, aiming to obtain the incentive of USD 15.00 per each reduced ton of $\mathrm{CO}_{2}$, offered by the Korean government [20]. In Turkey, the improvements in thermal treatment and zinc phosphatizing processes required investment of USD 34 thousand, which was returned in 28 months by means of the annual reductions of $32,647 \mathrm{kWh}(36 \%)$ of energy, $1,401 \mathrm{~kg}(26.1 \%)$ of chemical materials, $18,831 \mathrm{~m}^{3}(34.1 \%)$ of water consumption, $3,255 \mathrm{~m}^{3}(50.9 \%)$ of wastewater treatment and $4,656 \mathrm{~m}^{3}(16.9 \%)$ of sludge generation [10].

In a Swedish truck manufacturer, the processes improvements resulted at reducing the steel scrap generation by $72 \%$, fluids by $14 \%$, fuels by $10 \%$ and hazardous metals by $3 \%$ [14]. In other truck manufacturer company, located in Portugal, CP had high impact on the design of the green supply chain, with relevant advantages to the social, economic and environmental factors [21]. In China, the accounting of GHG emissions revealed that engine remanufacturing has increased economic value and reduced GHG emissions [22]. In Brazil, the improvements on manufacturing parameters of the exhaust valves resulted in cost saving and reduction of $27 \%$ impact on the natural resources depletion, mainly related to energy, raw material and cutting fluid [23].

Despite the Cold Test has been widely used by manufacturers, there is a lack of study for accounting the economic and environmental advantages of this process. Then, this research gap motivated the following questions: Is Cold Test a cleaner production practice? How advantageous is Cold Test in terms of ecoefficiency compared to Hot Test? The research objectives have driven the investigation to find out the answer for these questions.

The overall aim was assessing the economic and environmental advantages at replacing the traditional Hot Test process by a Cold Test machine for checking performance and leakage of Diesel engines in the assembly line. To reach the main objective, the gathering of the economic and environment data before and after the new process implementation allowed stablishing a comparison between the processes and verifying the economic feasibility of the Cold Test acquisition.

This paper is organized as follows: the research methodology applied is presented in section 2; the case study with results of the economic and environmental assessment is in section 3; the discussion of results in section 4; finally, conclusions of this work, 
limitations and recommendations for futures investigations are in section 5 .

\section{Methodology}

The case study was an exploratory investigation in a Diesel engines manufacturer installed in Brazil. The exploratory approach is an initial step to understand a phenomenon when the subject matter does not allow definitive conclusions [24]. Furthermore, case study has presented significant contributions in the practical and theoretical fields [25], revealing a powerful research methodology in operations management [26].

The investigation started by collecting information on the Hot Test process, from January to December of 2016. The purpose of this study was identifying the operational costs and environmental impacts involved on this activity. The estimation of Cold Test data took into account a machine installed in other plant of the same company. The assessment done by this study consisted at comparing the economic and environmental aspects of two scenario: (i) checking all manufactured engines in Hot Test; (ii) implementation of Cold Test for the final checking of $95 \%$ produced engines and the remaining of $5 \%$ engines in Hot Test.

The economic assessment consisted at calculating the Return on Investment (ROI) for acquisition of Cold Test machine. Managers usually analyse de feasibility of investments through the ROI analysis [27]. The ROI indicates the required time to recover the investment. The calculation consists in the division of the profit over a period, by the investment [28].

The accounting of environmental advantages used the Mass Intensity Factor (MIF) methodology, which allows measuring the impact in the abiotic, biotic, water and air compartments [29]. The biotic compartment approaches the living organisms, such as plants and decomposers; the abiotic compartment is a set of non-living ecosystem factors, which acts on the biotic medium, made up of measures such as temperature, pressure, precipitation and geographical relief [30].

The use of MIF methodology were present in papers that emphasized its relevance. MIF is an appropriate tool to measure the total environmental impact caused by manufacturing systems [31,32]. The use of MIF, along with other environmental evaluation tools can bring significant results for stakeholders, either for immediate and local evaluation or to preview future impacts upon nature [33]. The MIF analysis associates the Mass (M) balance with the Intensity Factor (IF) of a substance to calculate the total envi- ronmental impact at the ecosystem [34].

The MIF calculation is shown in Eq. (1).

$$
\mathrm{MIF}=(\mathrm{M} \times \mathrm{IF})
$$

The calculation of the environmental impact reduction per compartment consisted in multiplying the factors of the compartments, abiotic (w), biotic $(\mathrm{x})$, water $(\mathrm{y})$, and air $(\mathrm{z})$, by the material mass balance. The Mass Intensity per Compartment (MIC) is shown in the Eq. (2).

$$
\begin{aligned}
& \mathrm{MIC}= \\
& (\mathrm{IF} \mathrm{Aw}+\mathrm{IF} \mathrm{Bw}+ \\
& \mathrm{IF} \mathrm{Cw}+\ldots+\text { IF Nw})
\end{aligned}
$$

\footnotetext{
Where:

IF Aw is the intensity factor of waste A in the abiotic compartment (w)

IF $\mathrm{Bw}$ is the intensity factor of waste $\mathrm{B}$ in the abiotic compartment (w) IF $\mathrm{Cw}$ is the intensity factor of waste $\mathrm{C}$ in the abiotic compartment (w) IF $\mathrm{Nw}$ is the intensity factor of waste $\mathrm{N}$ in the abiotic compartment (w)
}

The MIC calculation for the biotic $(\mathrm{x})$, water $(\mathrm{y})$ and air $(\mathrm{z})$ compartments used the same procedure. The sum of all MICs resulted the Mass Intensity Total (MIT), as described in Eq. (3).

$$
\begin{aligned}
& \mathrm{MIT}= \\
& (\mathrm{MICw}+\mathrm{MICx}+ \\
& \mathrm{MICy}+\mathrm{MICz})
\end{aligned}
$$

The materials used for the Hot Test were Diesel oil, electricity, engine coolant fluid and oil for hydraulic system. Diesel oil is the fuel used to run engines during the checking. Electricity is the energy power required for dynamometer. The coolant is the fluid that circulates inside the engine to keep the temperature under control. The calculation of the air compartment for Diesel required the sum of the intensity factors before (0.02) and after (3.20) combustion, due to the oxygen consumption. Thus, the intensity factor of Diesel is 3.22 in the air compartment. The substance of engine coolant is ethylene glycol and the oil for hydraulic system is naphtha. The values of Intensity factors used in this study are shown in table 1 . 
Table 1. Intensity Factors of materials used in the study

\begin{tabular}{|c|c|c|c|c|}
\hline Used Material & Abiotic & Biotic & Water & Air \\
\hline - Diesel & 1.36 & - & 9.7 & 3.22 \\
\hline - Electricity & 3.15 & 0.04 & 57.64 & 0.514 \\
\hline $\begin{array}{l}\text { - Coolant fluid } \\
\text { \ Ethylene glycol }\end{array}$ & 2.9 & - & 133.46 & 2.29 \\
\hline $\begin{array}{l}\text { - Oil for hydraulic system } \\
\text { Naphtha }\end{array}$ & 1.69 & - & 13.88 & 0.05 \\
\hline
\end{tabular}

\section{Case Study}

The case focus of this study was a Brazilian factory that produces Diesel engines for several applications such as buses, trucks, tractors, boats and generators.

\subsection{Hot Test Process Description}

The Hot Test was a final checking of engines before deliver them to the customers. Its purpose was to check parameters of performance and leakage to assure that the engines met customer specification. To measure performance of an engine needs to connect the engine to a dynamometer to control the speed and load. This process checks parameters of engine speed, engine torque, fuel flow rate, airflow rate, cylinder pressure, oil temperature, coolant temperature, the fuel injection timing and emissions. The testing procedure consisted of operating the engine at different speeds and loads. The preparation to perform the Hot Test consisted in to fill the lubricant oil pan and to connect hoses of intake air, exhaust gases and engine coolant fluid. The total time required to the Hot Test was eighteen minutes per engine.

The assembly line was compound of forty workstations. The takt time was five minutes per workstation. Due to the time required to the test $(18 \mathrm{~min})$ was longer than the takt time of the main line (5min), there were four Hot Test rooms running in parallel. After the test, the operators disconnect the hoses used in the test for intake air, exhaust gases and coolant fluid. When the test approves the engine, the operator carries the engine to the final assembly process that consists in to assemble the front and rear engine supports. Then, the engines are stored in the warehouse. In case of failure detection during the test, the operator carries the engine to the rework station for the failure analysis and repair. A new test is required after the rework. The process flowchart with Hot Test process is shown in figure 1 .

\subsection{Cold Test Process Description}

The Cold Test consists in verifying the parameters of customer requirements by means of electronic sensors. In engine Cold Test, electric motor is used to rotate the crankshaft of the engine, which means no fuel consumption. The test involves analysis of mechanical characteristics, oil system, fuel system, ignition system, EGR valve, sensors and vibration. Specifically, the checked parameters are engine torque, oil pressure, intake pressure, exhaust pressure, rotation and synchronism of crankshaft, vibration, fuel injection pressure and rail pressure. By comparing

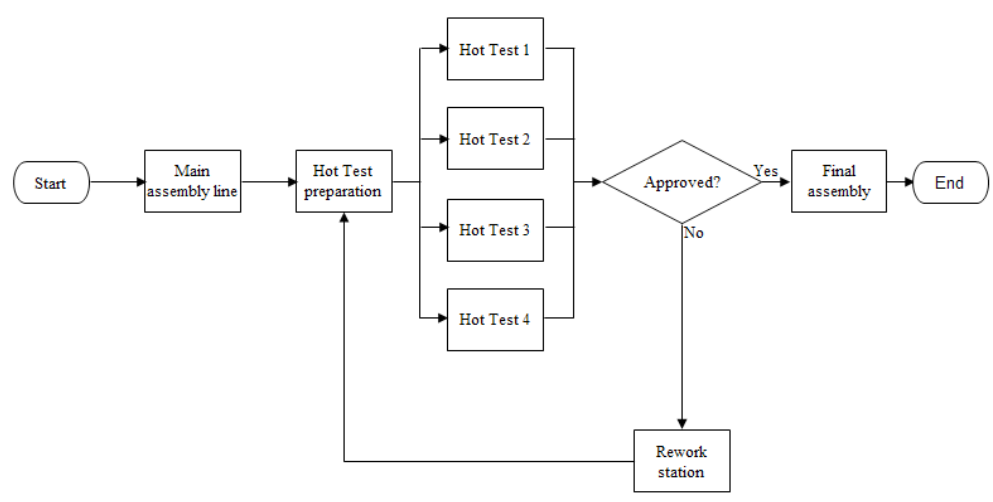

Figure 1. Process Flowchart with Hot Test 
the waveforms with good engine, their common characteristics are identified to approve or reject the product.

The test cycle time is three minutes, shorter than the takt time of the assembly line. For this reason, a single Cold Test machine is enough for checking all engines without impact in the plant productivity. The process flowchart with Cold Test is illustrated in the figure 2 .

\subsection{Economic Advantages of Cold Test Machine}

The economic analysis took into account the operational costs of Hot Test in 2016, by a production volume of 21,544 engines, and an estimation of the Cold Test. The implementation of Cold Test covered $95 \%$ of engines in the final checking, remaining a 5\% sample that were run in Hot Test as a product audit process. For this reason, the inputs used in Hot Test such as coolant fluid and oil for hydraulic system were in the costs estimate of Cold Test. The economic data of Hot Test and Cold Test are shown in table 2.

The annual cost was USD 580,569 to run the Hot Test and USD 22,556 with Cold Test machine. Thus, the cost saving by the adoption of Cold Test was USD 558,013 per year. The investment for the Cold Test machine acquisition was USD 2.1 millions. The division of required investment by the cost

Table 2. Economic data of Hot Test and Cold Test per year

\begin{tabular}{ccc}
\hline Used material & Hot Test (USD) & Cold Test (USD) \\
\hline Electricity & 285.610 & 7.808 \\
Diesel & 166.371 & 8.319 \\
Coolant fluid & 116.217 & 5.811 \\
$\begin{array}{c}\text { Oil for hydraulic } \\
\text { system } \\
\text { Total }\end{array}$ & 12.371 & 619 \\
\hline
\end{tabular}

saving resulted the period to return on investment. Thus, these figures pointed out a period of three years and ten months for getting back the investment.

\subsection{Environmental Advantages of Cold Test Machine}

The analysis of the advantages for the ecosystem consisted in accounting the reduction of environmental impact obtained by reducing material consumption and energy with the use of Cold Test machine. The collecting data took the annual reduction of Diesel, coolant fluid, oil for hydraulic system and electricity. The values of liquids density were required to convert the data collected in volume to mass. The mass intensity per compartment (MIC) was determined by multiplying the quantity of each material by its respective mass intensity factor (MIC).

The mass intensity total (MIT) was determined as the sum of the MIC of the abiotic-biotic-water-air compartments. For instance, the use of Cold Test meant the reduction of $268,435 \mathrm{~kg}(318,428$ liters) of Diesel fuel. Nevertheless, the MIF analysis pointed out the advantages for environment were higher than the showed by the traditional mass balance. The MIF indicated reduction of $365,071 \mathrm{~kg}$ in abiotic system, $2,603,818$ in water, and 864,360 in air. The data of annual reduction, mass balance and MIT are shown in table 3.

In additional to the MIF, the environmental analysis took into account the emission of exhaust gases, $\mathrm{CO}, \mathrm{HC}, \mathrm{NOX}, \mathrm{CO} 2$ and particulate material. Particulate material is any substance present in the atmosphere, except the water, with microscopic dimensions larger than molecular dimensions [36]. The average emission of gases was collected in monthly reports provided to the governmental agency for the environmental protection. The average of the measurements times the number of produced engines in 2016 resulted the total of $848,651 \mathrm{~kg}$ of gases emis-

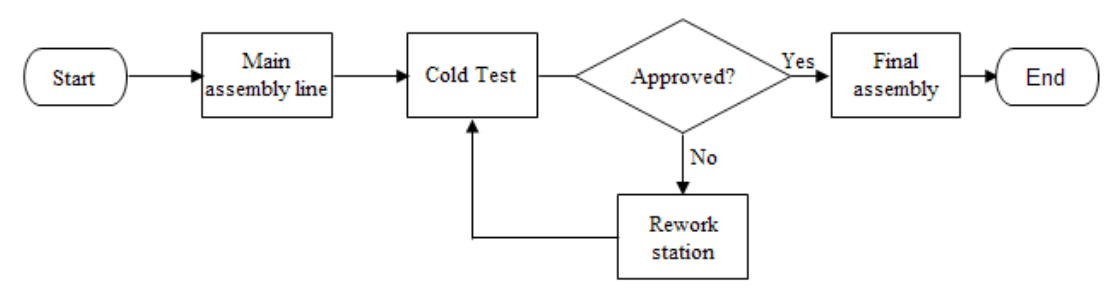

Figure 2. Process Flowchart with Cold Test 
sion, mainly $\mathrm{CO}_{2}$. The quantity of average emission of gases and the mass released to the atmosphere are presented in table 4 .

The environmental advantages calculated by the mass balance resulted in the Total Material Saving (TMS) of 323,540 $\mathrm{kg}$ per year. The MIT resulted the reductions of $177,571,656 \mathrm{~kg}$ of material and 848,651 $\mathrm{kg}$ of GHG emissions, with total of $178,420,307 \mathrm{~kg}$ resources conservation. The discrepancy of values denotes that MIF methodology makes a complete analysis of ecosystem. The environmental impact estimated by mass balance is few significant compared to MIT value.

\section{Discussion}

The results indicated that Cold Test machine is a CP practice that returned operational cost saving and reduction of environmental impact. This initiative improved the efficiency use of resources for the final checking process of Diesel engines. The implementation of $\mathrm{CP}$ practices confirmed those reported by $[12,13,14]$.

The CP actions decreased sharply the consumption of electricity, Diesel fuel, coolant fluid and oil for hydraulic system, which resulted savings of USD 558,013 per year. The investment of USD 2.1 mil- lion for Cold Test acquisition returned in 3 years and 10 months. With regard to economic advantage, other studies on automotive industry pointed out gains through the efficiency use of fuel and fluids [14], energy $[9,17,18,21]$ and water $[9,15,16]$. This result awakens the interest of managers to find out solutions that link process improvements and cost saving. This case was an example that investments in new technology return reduction of operational costs. In addition, managers could account gains of quality and productivity.

The environmental advantages calculated by means of MIF methodology indicated significant reduction of environmental impact, 178,420,307 $\mathrm{kg}$ of resources conservation. This figure was higher than the value found in the mass balance calculation, 323,540 kg. Despite the accuracy of MIF to account environmental impact, none study on $\mathrm{CP}$ in automotive industry used it. The environmental assessment of previous studies took into account the mass balance method $[9,14,21]$ and $\mathrm{CO}_{2}$ emissions accounting $[18,20]$. This finding enhances the relevancy of disseminating widely the MIF methodology for environmental assessment. In terms of practical implications, manufacturing managers and practitioners could use this studyas example to broaden their understanding of how to account the environ-

Table 3. Environmental advantages by the adoption of Cold Test

\begin{tabular}{|c|c|c|c|c|c|c|c|}
\hline Used Material & $\begin{array}{l}\text { Annual } \\
\text { reduction }\end{array}$ & $\begin{array}{l}\text { Density } \\
{[\mathrm{kg} / \mathrm{l}]}\end{array}$ & Mass [kg] & Abiotic & Biotic & Water & Air \\
\hline - Diesel & $\begin{array}{l}318,428 \\
\text { liters }\end{array}$ & 0.843 & 268,435 & 365,071 & - & $2,603,818$ & 864,360 \\
\hline $\begin{array}{l}\text { - Coolant fluid } \\
\text { ^ Ethylene glycol }\end{array}$ & 42,914 liters & 1.122 & 48,150 & 139,634 & - & $6,426,033$ & 110,262 \\
\hline $\begin{array}{l}\text { - Oil for hydraulic system } \\
\text { • Naphtha }\end{array}$ & 7,995 liters & 0.870 & 6,955 & 11,755 & - & 96,544 & 348 \\
\hline - Electricity & $\begin{array}{l}2,721,600 \\
\text { kWh }\end{array}$ & - & - & $8,573,040$ & 108,864 & $156,873,024$ & $1,398,902$ \\
\hline MIC & & & & $9,089,500$ & $108,864.00$ & $165,999,419$ & $2,373,873$ \\
\hline \multicolumn{8}{|l|}{$\mathrm{MIT}=177,571,656 \mathrm{~kg}$} \\
\hline TMS & & & 323,540 & & & & \\
\hline
\end{tabular}

Table 4. Accounting of gases emission per year

\begin{tabular}{lcc}
\hline Gases & Average emission $[\mathrm{g} / \mathrm{kWh}]$ & Mass/year $[\mathrm{kg}]$ \\
\hline $\mathrm{CO}$ & 0.055 & 70 \\
$\mathrm{HC}$ & 0.023 & 29 \\
$\mathrm{NO}_{\mathrm{x}}$ & 1.746 & 2,216 \\
$\mathrm{CO}_{2}$ & 666.886 & 846,313 \\
Particulate material & 0.018 & 23 \\
Total & & 848,651 \\
\hline
\end{tabular}


mental impact of $\mathrm{CP}$ actions implemented in their production systems.

The evaluation of social benefits was out of this study. However, non-accountable advantages were observed after the Cold Test implementation for final checking process of Diesel engines. Lower level of noise and risks of accidents increased the safety and health of operators. Moreover, the positive effects caused by CP improvements got stronger the motivation of workers. The relevance of social demands in corporate decision-making highlight the integration of social factor to $\mathrm{CP}[8,11]$. Thus, a profit-driven company reached cost saving through $\mathrm{CP}$ actions that carried on environmental and social benefits. In this sense, managers could disclosure social and environmental figures in order to show to society their friendly operations, which add value to company brand as a competitiveness advantage.

\section{Conclusion}

This study showed the economic feasibility for the Cold Test machine acquisition with the return on investment in medium-term. Furthermore, the accounting of environmental impact through the MIF methodology emphasized that the benefits for the ecosystem conservation were even higher than the figures estimated by means of the mass balance method. Moreover, the replacement of Hot Test decreased the level of pollutants that cause harmful effect on human health. Therefore, the advantages reached in the economic, environmental and social dimensions revealed that the Cold Test machine was a solution for increase the sustainability level of the factory.

Despite the several benefits of the Cold Test, important requirements such as leaks and test in the turbo compressor require Hot Test. Then, Cold Test is not able to detect these types of failures in Diesel engines. The Cold Test identifies defects caused in assembly process such as bolts without torque, lack or exchange of components. Considering it, Cold Test and Hot Test are complementary processes. Thus, the company strategy for checking $95 \%$ of engines in Cold Test and 5\% in Hot Test, as product audit, was the best solution in terms of economic, environmental, process reliability and quality.

The theoretical contribution for the science relies at disseminating the MIF methodology and its accuracy to calculate the total environmental impact, which takes into account four compartments of ecosystem: biotic, abiotic, water and air. Then, there is opportunity for future studies evaluate the environmental benefits by means of MIF methodology instead of the mass balance method.

The contribution for the practical field consisted of showing a case study that achieved economic gain and environmental advantages by adopting Cleaner Production. In addition, the achievement of non-monetary advantages by the adoption of Cleaner Production such as safety and occupational health for operators and positive value for the brand image. Cleaner Production is an environmentally friendly way to obtain cost saving in industrial operations. In this context, managers and practitioners could use the method presented in this study to calculate the total of environmental impact on its operations.

The assessment is capable of further improvements by analysing in-depth the social advantages such as noise emissions and job satisfaction. Thus, the recommendation for future investigations is to assess the economic, environmental and social advantages of the Cold Test for checking of engines in other factories.

\section{Funding}

This research did not receive any specific grant from funding agencies in the public, commercial, or not-for-profit sectors.

\section{References}

[1] Delvecchio S, D'Elia G, Dalpiaz G (2015) On the use of cyclostationary indicators in IC engine quality control by cold tests. Mechanical Systems and Signal Processing 60,208-228.

[2] Fogaça P, Souza DL, Manéa F (2018) Comparison between Cold and Hot Test procedures in a company manufacturer of diesel engines. Gestao \& Produçao 25, 343-353.

[3] Ante G, Facchini F, Mossa G, Digiesi S (2018) Developing a key performance indicators tree for lean and smart Production systems. IFAC PapersOnLine, 51(11), 13-18.

[4] Facchini F, Mummolo G, Mossa G, Digiesi S, Boenzi F, Verrielo R (2016) Minimizing the Carbon Footprint of Material Handling Equipment: Comparison of Electric and LPG Forklifts. Journal of Industrial Engineering and Management, 9(5), 1035-1046.

[5] Oliveira Neto GC, Tucci HNP, Pinto LFR, Costa I, Leite RR (2016) Economic and Environmental Advantages of Rubber Recycling. IFIP Advances in Information and Communication Technology, v.1, 19-27.

[6] Briem Ak, Betten T, Held M, Wehner D, Baumann M (2019) Environmental Sustainability in the Context of Mass Personalisation - Quantification of the Carbon Footprint with Life Cycle Assessment. International Journal of Industrial Engineering and Management, 10(2), 171-180.

[7] Froehlich JW, Henger KA (2007) Engine Technology International IN: Cold Testing Of IC Engines. Dorking: Ukip Media \& Events Ltd.

[8] UNEP - United Nations Environment Program (1993) Our Planet: Cleaner Production Makes Money, 5. UNEP, 
Nairobi, p. 3.

[9] Glavic P, Lukman R (2007) Review of sustainability terms and their definitions. Journal of Cleaner Production, 15, 1875-1885.

[10] Alkaya E, Demirer GN (2013) Greening of production in metal processing industry through process modifications and improved management practices. Resources, Conservation and Recycling, 77 (1), 89-96.

[11] Oliveira Neto GC, Pinto LFR (2019) Drivers to Promote Sustainability as Operational Strategy: Cross Content Analysis. Journal of Environmental Accounting and Management, 7(4), 395-408.

[12] Guimarães JCF, Severo EA, Vasconcelos CRM (2018) The influence of entrepreneurial, market, knowledge management orientations on cleaner production and the sustainable competitive advantage. Journal of Cleaner Production, 174, 1653-1663.

[13] Godina R, Matias JCO, Azevedo SG (2016) Quality Im provement With Statistical Process Control in the Automotive Industry. International Journal of Industrial Engineering and Management, 7(1), 1-8.

[14] Telukdarie A, Buckley C, Koefoed M (2006) The importance of assessment tools in promoting cleaner production in the metal finishing industry. Journal of Cleaner Production, 14 (18), 1612-1621.

[15] Orsato RJ, Wells P (2007) U-turn: the rise and demise of the automotive industry. Journal of Cleaner Production, 15 (11/12), 994-1006.

[16] Kurdve M, Zackrisson M, Wiktorsson M, Ulrika Harlin U (2014) Lean and green integration into production system models - experiences from Swedish industry. Journal of Cleaner Production, 85, 180-190.

[17] Sans R, Ribo M, Alvarez D, Forné C, Puig MD, Puig F (1998) Minimization of water use and wastewater contaminant load. Journal of Cleaner Production 6 (3/4), 365-369.

[18] Taylor B (2006) Encouraging industries to assess and implement cleaner production measures. Journal of Cleaner Production, 14, 601-609.

[19] Khan Z (2008) Cleaner production: an economical option for ISO certification in developing countries. Journal of Cleaner Production, 16 (1), 22-27.

[20] Lee KH (2012) Carbon accounting for supply chain management in the automobile industry. Journal of Cleaner Production, 36 (1), 83-93.

[21] Govindan K, Azevedo SG, Carvalho H, Cruz-Machado V (2014) Impact of supply chain management practices on sustainability. Journal of Cleaner Production, 85, 212-225.

[22] Shi J, Fan S, Wang Y, Cheng J (2019) A GHG emissions analysis method for product remanufacturing: A case study on a diesel engine. Journal of Cleaner Production, 206, 955-965.

[23] Lopes Silva DA, Oliveira JA, Filleti RAP, Oliveira JFG, Silva EJ, Ometto AR (2018) Life Cycle Assessment in automotive sector: A case study for engine valves towards cleaner production. Journal of Cleaner Production, 184, 286-300.

[24] Yin RK (2014) Case study research: design and methods. Sage, California.

[25] Barrat M, Choi TY, Li M (2011) Qualitative case studies in operations management: Trends, research outcomes, and future research implications. Journal of Operations Management 29(4), 329-342.

[26] Voss C, Tsikriktsis N, Frohlich M (2002) Case research in operations management. International Journal of Operations \& Production Management, 22.

[27] Oliveira Neto GC, Chaves LEC, Pinto LFR, Santana JCC, Amorim MPC, Rodrigues MJF (2019) Economic, Environmental and Social Benefits of Adoption of Pyrolysis
Process of Tires: A Feasible andEcofriendly Mode to Reduce the Impacts of ScrapTires in Brazil. Sustainability, $11,1-18$.

[28] Gitman LJ, Zutter CJ (2010) Principles of Managerial Finance. Prentice Hall, Boston.

[29] Ritthof M, Rohn H, Liedtke C (2002) Calculating MIPS: Resource Productivity of Products and Services. Wuppertal Spezial 27.

[30] Odum, E.P. 1998. Ecologia Rio de Janeiro: Guanabara Koogan (in Portuguese).

[31] Federici M, Ulgiati S, Basosi R (2008) A thermodynamic, environmental and material flow analysis of the Italian highway and railway transport systems. Energy, 33, 760-775.

[32] Oliveira Neto GC, Sousa WC (2014) Economic and Environmental Advantage Evaluation of the Reverse Logistic Implementation in the Supermarket Retial. IFIP - Advances in information and Communication Technology, 439(1), 197-204.

[33] Spinelli D, Jez S, Pogni R, Basosi R (2013) Environmental and life cycle analysis of a biodiesel production line from sunflower in the Province of Siena (Italy). Energy Policy, 59, 492-506.

[34] Oliveira Neto GC, Correia AJC, Schroeder, AM (2017) Economic and environmental assessment of recycling and reuse of electronicwaste: Multiple case studies in Brazil and Switzerland. Resources, Conservation \& Recycling, $127,42-55$.

[35] Wuppertal Institute(2015) Table of Material Intensity, Fuels, Transport Services and Food. Wuppertal Institute, Dusseldorf.

[36] De la Torre A, Barbas B, Sanz P, Navarro I, Artíñano B, Martínez MA (2018) Traditional and novel halogenated flame-retardants in urban ambient air: Gasparticle partitioning, size distribution and health implications. Science of the Total Environment, 630, 154-163. 